\title{
SUPREMO TRIBUNAL FEDERAL COMO ATOR COM PODER DE VETO: UMA ANÁLISE A PARTIR DA OBRA DE GEORGE TSEBELIS.
}

\section{Claudio Ladeira de Oliveira ${ }^{1}$ Samuel Martins Santos ${ }^{2}$}

\begin{abstract}
Resumo: O presente artigo tem como objetivo apresentar uma metodologia de análise dos tribunais constitucionais no campo do Direito Constitucional, em leitura interdisciplinar com a Ciência Política. Destacadamente, com vistas aos estudos sobre o funcionamento e a atuação do Supremo Tribunal Federal no Brasil, considerando o desenho da Constituição Federal de 1988. O problema trata da possibilidade de identificação do Supremo Tribunal Federal como um ator com poder de veto, tendo como referencial teórico metodológico a obra de George Tsebelis. A hipótese considera possível tal opção metodológica, e objetiva identificar seu potencial de análise para a compreensão das relações entre os poderes da república no Estado brasileiro contemporâneo. O método utilizado é bibliográfico, com análises institucionais, do que resulta a conclusão da ampla possibilidade de aplicação de tal marco teórico, como também a necessidade de algumas precauções para o aprimoramento do seu potencial analítico em relação ao Poder Judiciário.
\end{abstract}

Palavras-chave: Supremo Tribunal Federal - Veto - Ator - Jurisdição - Constituição

“(...) quanto maior for o número de grupos discordantes que formam a maioria, tanto mais árdua será a tarefa de agradar a todos, e mais fraca e instável será a posição do gabinete."

LAURENCE LOWEL (1896, p. 73-74)

\section{Introdução}

O artigo identifica a separação dos poderes como um ponto nuclear do funcionamento dos Estados contemporâneos de configuração democrática. Neste contexto, a projeção do Poder Judiciário nos Estados constitucionais enfatizou a importância de pesquisas sobre a separação dos poderes e a busca por metodologias adequadas para a compreensão dos tribunais constitucionais.

\footnotetext{
1 Professor Doutor do Programa de Pós Graduação em Direito da Universidade Federal de Santa Catarina. Universidade Federal de Santa Catarina - UFSC, Santa Catarina. Brasil. E-mail: samuelmartinsdossantos.1977@gmail.com

${ }^{2}$ Doutorando em Direito pela Universidade Federal de Santa Catarina, mestre em Teoria e Filosofia do Direito da Universidade Federal de Santa Catarina, docente do Complexo de Ensino Superior de Santa Catarina, na graduação e especialização, das disciplinas de Direito Constitucional, Direito Urbanístico e Direito das Coisas, docente de Processo Constitucional de especialização de Direito Público da Estácio de Sá e docente de Direito das Coisas na especialização de Direito Civil e Processo Civil da UNOESC/Joaçaba, advogado inscrito na secção de Santa Catarina, OAB/SC. n. 26.336, membro do grupo Direito e Política da UNICAMP e graduado em Direito pela Universidade Estadual Paulista Julio Mesquita Filho. Universidade Federal de Santa Catarina - UFSC, Santa Catarina. Brasil. E-mail: claudio.ladeira@ufsc.br
} 
No Brasil, desde a promulgação da Constituição Federal de 1988 as ciências sociais têm reconhecido no Supremo Tribunal Federal uma instituição relevante para pesquisas sobre a experiência democrática recente.

Nesta corrente é possível indicar períodos com predominância de trabalhos a partir de recortes específicos, na seara do Direito foram marcantes análises sobre o funcionamento do Supremo Tribunal Federal a partir da Teoria do Direito, Direito Constitucional e Teorias da Argumentação, tais trabalhos foram caracterizados pelos esforços na identificação de critérios de racionalidade na produção jurisdicional da corte (OLIVEIRA, 2006).

Estas pesquisas foram influenciadas por uma forte pauta normativa, na qual os marcos teóricos definiam critérios de racionalidade para as decisões judiciais e posteriormente os pesquisadores justapunham tais critérios às decisões do Supremo Tribunal Federal. Comumente os resultados obtidos indicam um baixo grau de racionalidade do exercício da jurisdição constitucional brasileira.

Por outro lado, a partir de pesquisas desenvolvidas na seara da Ciência Política, também é possível destacar trabalhos sobre o ativismo judicial, judicialização da política e politização da justiça, temáticas que posteriormente foram incorporadas pelas agendas de pesquisas das ciências jurídicas (KOERNER, 2017).

O presente trabalho tem como objetivo testar um referencial metodológico para análise das Cortes Constitucionais, destacadamente, o Supremo Tribunal Federal no Brasil no desenho da Constituição Federal de 1988. Trata-se da obra de George Tsebelis, professor de Ciência Política da Universidade de Michigan (EUA), que a partir de referenciais da Teoria dos Jogos e da Teoria da Ação Racional desenvolveu a Teoria dos Atores com poder de veto como uma metodologia para análise do funcionamento das instituições políticas.

Em que pese tratar-se de um referencial teórico advindo da Ciência Política, a sua aplicação nas mais variadas searas das Ciências Sociais tem comprovado seu potencial analítico. E, como pretende-se comprovar no decorrer do artigo, o modelo institucional previsto na Constituição Federal de 1988 para o Supremo Tribunal Federal possibilita a utilização do referido método sem que ocorra a perda do referencial epistemológico das ciências jurídicas.

Feita esta introdução, o presente artigo tem como problema de partida a seguinte formulação: Considerando a obra de George Tsebelis, e o desenho institucional da Constituição Federal de 1988, o Supremo Tribunal Federal pode ser considerado um ator com poder de veto? A hipótese é uma resposta afirmativa a esta pergunta, ainda que tal formulação não esteja contida expressamente na obra do autor, pretende-se comprovar tal possibilidade, assinalar seu potencial e 
indicar sua pertinência para pesquisas sobre a atuação do Poder Judiciário no âmbito das ciências jurídicas.

\subsection{Teoria dos atores com poder de veto}

O trabalho de George Tsebelis encontra-se inserido no contexto do institucionalismo, possuindo como figura central os atores com poder de veto, que são caracterizados como atores cuja a discordância sobre determinada temática pode impedir uma alteração significativa do sistema jurídico e político.

O pressuposto do autor encontra-se na frase de Lawrence Lowel disposta no início do presente artigo, qual seja, quanto maior o número de atores com poder de veto mais difícil será a obtenção de consensos para mudanças institucionais.

Um conceito relevante na sua proposta é a estabilidade decisória, que pode ser identificada como as tendências de um sistema jurídico e político à permanência, ou, em sentido inverso, as resistências e obstruções oferecidas por tal sistema as mudanças.

Neste ponto, importa destacar que as mudanças institucionais como também a direção de tais mudanças não faz parte do objeto de estudo do autor, como justificativa para tal opção, dispõe:

(...) meu argumento se concentra nas instituições e nos seus efeitos. Embora alguns pesquisadores tentem abordar as implicações políticas específicas de certas instituições, acredito que resultados específicos são produto das instituições dominantes e das preferências dos atores envolvidos. Em outras palavras, as instituições são como conchas, e os resultados específicos que produzem dependem dos atores que as ocupam (TSEBELIS, 2009, p.24).

Além de excluir mudanças institucionais do seu objeto de análise, e enfocar a estabilidade decisória, devemos destacar que não existe uma análise de mérito do autor em relação à qualidade do sistema político que tende a permanência. Justamente por isto, a principal característica do seu trabalho é de viés metodológico, possibilitando a mais ampla utilização em regimes democráticos, regimes autoritários, sistemas de governo presidencialistas e parlamentaristas, ou análises institucionais circunscritas ao âmbito de um único Estado, nas relações entre os poderes da república, como se pretende desenvolver no presente artigo.

Exposta a hipótese da teoria, e sua principal variável, a estabilidade decisória, importa dispor uma tipologia dos atores com poder de veto contida na obra de George Tsebelis, para depois apresentar seus principais conceitos.

Os atores individuais podem ser formados por um único individuo, como é o caso do titular do Poder Executivo em um sistema de governo presidencialista puro, ou um colegiado que apenas 
se manifesta por unanimidade, ou colegiados com maiorias monolíticas, estes dois últimos exemplos são muito raros em regimes democráticos.

Os atores coletivos são colegiados plurais, sem a formação de blocos monolíticos estáveis, tais atores decidem por procedimentos deliberativos majoritários, sendo o exemplo mais claro a composição do Poder Legislativo. Tal instituição apresenta uma grande diversidade no seu colegiado e também procedimentos deliberativos diversos a depender do objeto, cujo o desenho pode impactar a atuação dos atores e a estabilidade decisória. A classificação de um ator como individual ou coletivo tem muita importância para o debate que ora se apresenta:

A transição dos atores individuais com poder de veto para os atores coletivos com poder de veto gera dois problemas. Primeiro, a configuração do conjunto vencedor do status quo pode se tornar complicada, isto é, os resultados da tomada de decisão se tornam mais complicados.(...)Segundo, atores coletivos com poder de veto violam uma suposição importante que fazemos sobre indivíduos: sob a regra da maioria, atores coletivos com poder de veto não podem escolher sem ambiguidade o resultado da sua preferência. Em outras palavras, as escolhas dos atores coletivos com poder de veto são ambíguas (TSEBELIS, 2009, p. 68).

A ambiguidade indicada pelo autor diz respeito as divergências que são absolutamente comuns em processos decisórios coletivos. Tal possibilidade, inclusive, é considerada um forte elemento democrático de um processo decisório, nos quais a liberdade dos indivíduos, e dos grupos que estão constitutivos desta coletividade, tendem a propiciar as mais amplas possibilidades de tomada de decisão

Como terceiro tipo, serão apresentados os atores formais com poder de veto, cuja a possibilidade de obstrução insuperável à uma mudança significativa do sistema jurídico político encontra-se expressamente prevista no desenho constitucional. $\mathrm{O}$ número de tais atores tende a ser constante, salvo hipótese de alteração do texto constitucional.

Considerando a Constituição Federal de 1988, é possível exemplificar como atores formais com poder de veto o Poder Executivo, e cada uma das casas do Poder Legislativo, pois todas estas instituições possuem competência para obstruir o trâmite legislativo e consequentes mudanças institucionais, sem necessidade de concordância por parte de nenhum outro poder, ainda que o veto do Poder Executivo seja relativo, nos termos do artigo 66 da Constituição Federal de 1988.

Os atores informais com poder de veto, por sua vez, não estão previstos expressamente no desenho constitucional, mas a sua atuação também pode se caracterizar como obstruções insuperáveis a mudança institucional, isto é, atores cuja a ausência de consenso corrobora para a manutenção da estabilidade decisória. 
Exemplificadamente, pode-se indicar um partido político com grande poder de coesão e um número significativo de membros como um ator informal com poder de veto, ou até mesmo um movimento social com uma capacidade de pressão, suficiente para obstruir uma pauta legislativa.

Em regra, os atores informais são objeto de estudo da Ciência Política. Excepcionalmente, conforme pretende-se demonstrar, é possível a caracterização de instituições jurídicas como atores informais com poder de veto.

Nesta sucinta apresentação, importa indicar a variável distância entre os atores como influente no processo decisório. Na análise de George Tsebelis, a localização dos atores e a distância institucional e ideológica entre eles tem impacto na sua influência sobre a estabilidade decisória do sistema jurídico e político.

E neste ponto destaca-se a regra da absorção, caracterizada pela inserção de um ator no sistema jurídico e político cujo o exercício do poder de veto não tem influência na estabilidade provisória. Neste caso o poder de veto é passível de ser contornado, absorvido, ou suspenso por parte dos demais atores, não impactando, por fim, na estabilidade decisória (TSEBELIS, 2009, p. $50)$.

Feita esta exposição inicial, torna-se pertinente a seguinte pergunta: qual a localização e o papel do Poder Judiciário na teoria dos atores com poder de veto na obra de George Tsebelis?

No clássico Veto players how political institutions work, publicado originalmente em 2002, consta um capítulo específico sobre o Poder Judiciário, particularmente os tribunais constitucionais.

A principal variável de análise do Poder Judiciário na obra de George Tsebelis é a sua independência em relação ao sistema político, como também a possibilidade do Poder Judiciário ser sobrestado pelos demais atores, por exemplo, quando há uma obstrução advinda deste poder passível de ser contornada por uma alteração legislativa, o que levaria a incidência da regra da absorção em relação ao Poder Judiciário.

Neste ponto, é importante indicar a diferença que George Tsebelis faz sobre decisões estatutárias do Poder Judiciário, ou regimentais, e as decisões decorrentes do exercício da jurisdição constitucional.

Na perspectiva do autor, quando o Poder Judiciário apresenta uma obstrução com fundamento em norma regimental o mesmo não se caracteriza como um ator com poder de veto, em função da possibilidade de absorção deste veto por parte dos demais atores. Em contrapartida, quando o tribunal constitucional apresenta uma obstrução como decorrente do exercício de jurisdição constitucional ter-se-ia a caracterização do Poder Judiciário como um ator com poder de veto: 
A essência desses argumentos está correta; tribunais constitucionais podem abolir legislação e, consequentemente, também são atores com poder de veto. Entretanto, as conclusões e predições sobre governos de juízes parecem exageradas. Por que? (...) Embora os juízes constitucionais sejam atores com poder de veto, na maior parte do tempo eles são absorvidos (TSEBELIS, 2009, p. 317).

A explicação apresentada pelo autor para tal posicionamento decorre da forma de nomeação dos membros das Cortes Constitucionais. A depender do modelo constitucional de nomeação dos ministros para as cortes constitucionais, a corte encontrar-se-ia inserida de tal modo no núcleo de unanimidade majoritário que a regra é a absorção e não o exercício do veto: "Afirmo que muitas vezes, os tribunais constitucionais se situam dentro do núcleo de unanimidade dos outros atores com poder de veto. A principal razão é o processo de nomeação para os cargos mais altos" (TSEBELIS, 2009, p. 319).

A análise apresentada pelo autor é cara ao debate constitucional brasileiro, marcadamente sobre as discussões em torno do ativismo judicial, ou interferências indevidas de um do Poder Judiciário nos demais poderes.

A análise do Poder Judiciário como um ator com poder de veto não faz parte do foco de George Tsebelis. E por qual motivo? Segundo o autor, e a partir dos exemplos que ele apresenta, a forma de indicação para a composição dos órgãos de cúpula do Poder Judiciário, como também as razões que servem de referência para a atuação dos seus membros no processo decisório caracterizase como uma verdadeira caixa preta, sic, razão pela qual ele não se detém neste ponto, visto que tais referências são, ao menos, mais explícitas no posicionamento e atuação dos atores no âmbito do Poder Legislativo e do Poder Executivo (TSBELIS, 2009, p. 319).

Ainda que o autor não aprofunde sua análise, pesquisadores reconhecem a existência de um pressuposto na forma de atuação do Poder Judiciário no seu modelo teórico, caracterizado pelo baixo exercício do poder de veto das instituições judiciais por decorrência da forma de seleção dos ministros dos tribunais superiores (ENGST; et al, 2013).

Tal hipótese tem muita convergência com a análise desenvolvida por Robert Dahl no artigo Decision-Making in a democracy: The Supreme Court as a national policy-maker, que possui o seguinte argumento central: "The fact is, then, that the policy views dominant on the Court are never for long out of line with the policy views dominant among the lawmaking majorities oh the United States" (1957, p. 285). ${ }^{3}$

\footnotetext{
3 Tradução livre:

“O fato é, então, que as visões políticas dominantes na Corte nunca estão por muito tempo em desacordo com as visões políticas dominantes entre as maiorias legislativas dos Estados Unidos” (1957, p. 285).
} 
Com isto é possível destacar dois pontos a serem retomados no referente a identificação do Poder Judiciário como um ator com poder de veto, a saber, a verificação do pressuposto da absorção de tais vetos por decorrência da forma de seleção dos seus membros, como também a análise do que o autor denomina de caixa preta (black box) como possibilidade de delimitação fronteiriça entre a Ciência Política e o Direito Constitucional.

Conforme pretende-se desenvolver, são justamente estas razões que delimitam uma zona fronteiriça entre a Ciência Política e o Direito Constitucional, mas tais limites não são impeditivos à utilização de tal metodologia para análise da Cortes Constitucionais como atores com poder de veto nas ciências jurídicas.

Neste ponto, vale mencionar um debate que existe entre os defensores do modelo atitudinal e seus críticos na Ciência Política norte-americana, que indicam as limitações das análises que sobrevalorizam as preferências políticas dos juízes no processo decisório. Em crítica aos trabalhos do modelo atitudinal de Segal e Spaeth, os defensores do institucionalismo vão indicar que as instituições possuem uma característica coercitiva sobre o comportamento dos atores, impedindo que as suas preferências políticas sejam manifestas sem nenhum tipo de restrição. A polarização neste ponto ocorre entre o modelo atitudinal e o modelo legal (KOERNER, 2017, p. 67).

Neste sentido, os trabalhos desenvolvidos por KRIZER e RICHARDS dão conta, com fundamentação teórica e empírica, que a jurisprudência é um elemento efetivamente considerado no processo decisório das cortes nos EUA. Neste sentido, os resultados indicam que uma alteração da jurisprudência tem impacto no seu processo decisório dos juízes, ainda que se mantenha a mesma composição no tribunal (2005).

Mesmo sem aprofundar o debate entre os defensores do modelo atitudinal e do modelo legal, o trabalho supracitado é importante para a questão que ora se apresenta no referente a delimitação de um campo de pesquisa nas ciências jurídicas que tenha como objeto as análises institucionalistas.

Tal afirmação ganha mais força quando se destaca que a principal referência do pensamento jurídico brasileiro é a escola romano-germânica, caracterizada por um forte critério positivo no processo decisório. Isto não nos possibilita afirmar que o método da subsunção tem aplicação escorreita na forma como os juízes decidem, mas certamente possui base suficiente para a construção de hipóteses no sentido de que as preferências políticas dos juízes são filtradas, ou buscam fundamentação, pela ordem jurídica positiva.

Este ponto aproxima o objeto de análise da seara das ciências jurídicas, e dispõe possibilidades de agendas de pesquisas sobre como as instituições jurídicas estruturam o comportamento dos juízes que possuem um pertinente potencial a ser explorado. Neste sentido tem sido desenvolvido o trabalho de Lee Epstein, que não resume as instituições à uma função 
coercitiva, pois reconhece nelas possibilidades de agir estratégico dos atores politicamente interessados (EPSTEIN; JACOBI, 2010).

Feitas estas observações, antes da análise da metodologia dos atores com poder de veto para estudo proposto, apresenta-se pertinente uma maior contextualização da obra de George Tsebelis, de modo que se possa avançar no teste do uso da sua metodologia para analisar cortes constitucionais, destacadamente, o Supremo Tribunal Federal no modelo brasileiro.

Como já ficou claro aos leitores mais atentos, a metodologia de análise institucional de George Tsebelis, que tem como objeto o processo decisório dos atores envolvidos, possui clara influência da Teoria dos Jogos e da Teoria da Ação Racional.

Estas referências são relevantes para que se possa apresentar um quadro mais completo da obra do autor, com a exposição do livro Jogos Ocultos: escolha racional no campo da política comparada, publicada no Brasil 1998, com publicação norte-americana original em 1990 com o título Nested Games: Rational Choice in Comparative Politics. ${ }^{4}$

A Teoria dos Jogos tem origem nas ciências exatas, sendo posteriormente inserida nas ciências sociais a partir da década de 50 para análises do comportamento de atores políticos. Com o uso de modelos que apresentam a conjugação entre variáveis, possibilidades de ações com ganhos e/ou perdas, a Teoria dos Jogos serve como base para análise de comportamentos institucionais e políticos. Nesta perspectiva os atores são mobilizados a partir dos payoffs, referindo-se ao ganho, pagamento, prêmio, ou sanção de cada ação.

Alguns modelos de análise são bastante conhecidos, como o dilema dos prisioneiros, o jogo da galinha, e outros, o analista desenvolve um suporte para a compreensão da movimentação dos atores em determinada arena.

Uma diferenciação feita pelo autor, que se apresenta importante na análise ora desenvolvida, diz respeito ao conceito de projetos institucionais, que não se confunde com o conceito de jogo, segundo o qual o ator que inova de modo a criar possibilidades de atuação não pré-existentes aumenta suas opções disponíveis. Em tal situação é necessário reconhecer que tal ator se encontra envolvido em um jogo na arena principal, mas também em um jogo sobre as regras do jogo (TSEBELIS, 1998, p. 23).

Outro pressuposto que é possível assinalar na obra de George Tsebelis, e na academia norteamericana de modo geral, é a grande influência da Teoria da Ação Racional, que tem em Jon Elster

\footnotetext{
${ }^{4}$ Nesta exposição alteramos a sequência das obras analisadas de George Tsebelis em consideração da maior proximidade da obra Veto Players (2000) com o objeto de análise, do que Nested Game (1990). Vale destacar as duas obras são absolutamente complementares, mas consideramos que a sequência da forma exposta possui maior didatismo.
} 
um dos seus principais formuladores. O pressuposto de tais analistas pode ser apresentado sucintamente da seguinte forma:

A escolha racional busca encontrar os melhores meios para fins dados. É um modo de adaptar-se otimamente às circunstâncias. (...) Aqui devemos notar que a escolha racional não é um mecanismo infalível, uma vez que a pessoa racional pode escolher apenas o que acredita ser o melhor meio (ELSTER, 1994, p. 41).

Estas duas influencias na obra de George Tsebelis são absolutamente próximas, e vão servir de base para a composição de métodos analíticos sobre possibilidades de ação, estratégia entre atores, potenciais de ganhos e comportamentos na hipótese de perdas.

A compreensão adequada da obra Jogos Ocultos (1998) imprescinde da lembrança de uma crítica recorrente à Teoria da Ação Racional, qual seja, o exacerbado racionalismo, que tende a afastar-se demasiadamente dos fenômenos em contextos históricos específicos, marcados por elementos de racionalidade e irracionalidade (REIS, 2000, p. 68).

George Tsebelis é um defensor da Teoria da Ação Racional, na obra Jogo Ocultos o autor reconhece limites da racionalidade de tal aporte teórico, mas desenvolve elementos que ele considera pertinentes para a superação deles e defesa deste aporte teórico. Se a teoria dispõe que os atores tendem a agir de modo a buscar o melhor resultado, o autor questiona: "Por que despertam curiosidade situações em que um ator escolhe uma alternativa que parece ir contra os seus próprios interesses, ou que pode não ser a melhor a escolher nas circunstâncias existentes? Por que elas necessitam de explicação?” (TSEBELIS, 1998, p. 17)

Os questionamentos apresentados pelo autor são absolutamente pertinentes, e possuem um forte potencial de contribuição para análise das instituições e do comportamento dos atores envolvidos.

A questão de fundo neste debate diz respeito aos limites da racionalidade ${ }^{5}$ como critério de compreensão dos fenômenos sociais, análises realistas, e seu potencial para a identificação de variáveis influentes e determinantes sobre comportamentos futuros dos atores em foco.

Na obra, George Tsebelis defende que eventuais incompatibilidades entre o que seria a escolha racional, ótima, definida pelo observador, e um comportamento disfuncional com tal parâmetro, por exemplo, uma escolha considerada pelo observador como subótima, ou errada, pode

\footnotetext{
5“A racionalidade nada mais é que uma correspondência ótima entre fins e meios. (...) Especificamente, os atores racionais devem ser coerentes (não possuir desejos ou crenças contraditórios), decidir de acordo com as regras do cálculo de probabilidades e interagir com outros atores de acordo com as presunções da teoria dos jogos. Em consequência, a questão sensata passa a ser não se as pessoas sempre se desviam da racionalidade, mas se as pessoas se the amoldam" (TSEBELIS, 1998, p. 34).
} 
indicar um limite informacional do observador e não necessariamente uma irracionalidade do comportamento do ator estudado. Conforme dispõe:

(...) o argumento principal deste livro é que, se, com informação adequada, a escolha de um ator parecer subótima, é porque a perspectiva do observador está incompleta. O observador centra sua atenção em apenas um jogo, mas o ator está envolvido em toda uma rede de jogos - o que chamo de jogos ocultos. O que parece subótimo a partir da perspectiva de um único jogo é na verdade ótimo quando é considerada toda a rede de jogos (TSEBELIS, 1998, p. 22).

Deste modo existe uma possibilidade de compreensão em perspectiva desta obra que identifica os limites e problemas da Teoria da Ação Racional, mas ao invés de simplesmente indicar uma eventual falta de racionalidade no comportamento do ator, George Tsebelis inverte a crítica para o próprio observador indicando a importância do mesmo considerar o seu limite informacional em relação ao ator estudado.

Conforme será demonstrado no próximo tópico, considerando as pesquisas nas ciências jurídicas, tal posição contém grande potencial para o desenvolvimento de análises realistas do funcionamento das instituições jurídicas de modo a prevenir-se da recorrente certificação de falta de racionalidade dos seus processos decisórios.

No debate sobre a pertinência da Teoria da Ação Racional para as ciências sociais, o autor reconhece que a racionalidade possui inegável dimensão normativa, pois a posição do observador identifica possibilidades ótimas de atuação ao ator em análise. Todavia, torna-se necessário destacar que sua proposta vai além desta dimensão normativa, incluindo a defesa da pertinência de tal metodologia para análises realistas dos fenômenos sociais.

Assim, além de possibilitar a visualização do dever ser na atuação dos atores analisados, segundo George Tsebelis, a Teoria da Ação Racional enseja a compreensão do comportamento dos atores e funcionamento das instituições em situações reais, possuindo ainda a possibilidade de identificação de variáveis influentes no seu comportamento e aumentar o nível previsibilidade sobre ações futuras:

No lugar do conceito de racionalidade como uma modelo de comportamento humano, proponho o conceito de racionalidade como um subconjunto de comportamento humano. A mudança de perspectiva é importante: não afirmo que a escolha racional pode explicar qualquer fenômeno e que não há lugar para outras explicações, mas sustento que a escolha racional é uma abordagem melhor para situações em que a identidade e os objetivos dos atores são estabelecidos, e as regras de interação são precisas e conhecidas pelos atores em interação (TSEBELIS, 1998, p. 43). 
Tais observações se apresentam como relevantes para contextualizar o sentido epistemológico do trabalho do autor, como também reconhecer seus limites e possibilidades.

Antes de adentrar no teste sobre limites e possibilidades da aplicação da metodologia desenvolvida por George Tsebelis para análises dos Tribunais Constitucionais, torna-se pertinente apresentar mais alguns elementos da obra Jogos ocultos: escolha racional no campo da politica comparada, inclusive porque estes são contributivos para os testes que faremos posteriormente.

Comumente a Teoria dos Jogos é pensada a partir da Teoria do Poder de Soma Zero, em tal composição o objeto de disputa entre dois ou mais atores é dividido a partir de relações entre ganho de um ator e perda do outro. Trata-se de um postulado que tem como referência o conflito, no qual o ganho de um ator encontra-se umbilicalmente atrelado a perda do outro ator.

Tal possibilidade interpretativa encontra-se presente na obra de Tsebelis, mas ele também destaca o princípio de Nash como uma possibilidade de interpretação das relações entre os atores envolvidos na qual os dois podem fazer escolhas com ganhos, sem ocorrer uma perda para o outro ator que faz parte da mesma arena.

O conceito de equilíbrio de Nash é o conceito fundamental para a teoria dos jogos. Os jogadores utilizam estratégias mutuamente ótimas em equilíbrio, realizam uma combinação estratégica da qual ninguém tem incentivo para desviar-se. Segundo esta definição, pode haver mais de um equilíbrio num jogo. O problema passa a ser o de escolher o mais razoável (1998, p. 42).

Isto para enfatizar que as relações entre os atores envolvidos não são exclusivamente de competição, e que o ganho recíproco pode ser uma possibilidade para a observância e manutenção das regras do jogo, o que faz muita diferença em análises institucionais.

Na sua defesa da Teoria da Ação Racional, George Tsebelis destaca dois elementos que podem variar os payoffs que mobilizam cada ator. Isto porque quando pensados a partir de uma arena e uma jogada exclusivas os payoffs tendem a ser constantes e conhecidos, todavia como o autor está pensando justamente atuações que podem ser concebidas como irracionais pelo observador ele apresenta a possibilidade de jogos reiterados e a existência de arenas múltiplas de atuação com variações dos payoffs que devem ser consideradas.

Inicialmente o autor destaca a possibilidade dos jogos reiterados, quando dois ou mais atores se encontram recorrentemente em uma mesma arena de atuação. Tal variável pode ter impacto no comportamento dos atores envolvidos, visto que cada jogo, com suas possibilidades de ganhos e perdas, é em regra pensado em lapsos temporais imediatos. Todavia os jogos reiterados possuem estratégias e lapsos temporais de médio e longo alcance, de modo que se apresenta absolutamente compreensível uma situação na qual um ator possa fazer uma opção subótima para uma jogo 
específico, que possa até mesmo lhe acarretar perdas, mas que na perspectiva de médio e longo prazo tal estratégia se apresente como a mais vantajosa.

No mesmo sentido, de possibilidade de variação dos payoffs, é a existência de arenas múltiplas, quando os atores envolvidos possuem possibilidades de ganhos, prêmios e sanções em mais de um âmbito de atuação.

Estes são dois elementos e limites da Teoria da Ação Racional, pois o observador nem sempre terá condições informacionais para identificar os jogos reiterados, os jogos ocultos e as arenas múltiplas de atuação dos atores envolvidos.

E, no entanto, quais as contribuições deste aporte teórico para a obra do autor? Neste ponto, o institucionalismo se apresenta marcante em sua análise, para o qual a previsibilidade das regras do jogo e das possibilidades de atuação dos atores envolvidos é um ganho substantivo potencializado por este marco teórico (TSEBELIS, 1998, p. 117).

As instituições são apresentadas como limites coercitivos à atuação dos atores, sendo a previsibilidade o grande ganho para todos envolvidos. A mobilização dos atores, portanto, é motivada pela maximização dos ganhos e minimização das perdas dentro do modelo institucional previamente delineado.

Considerando o papel fundamental das instituições no fortalecimento da previsibilidade, o autor indica como critério para o reconhecimento de instituições eficientes a sua condição para o impulsionamento de resultados que melhorem a situação para todos (ou quase todos) os jogadores, com a solução de problemas de coordenação elas podem possibilitar aumento de previsibilidade e competição entre os atores envolvidos dentro da observância das regras do jogo (TSEBELIS, 1998, p. 112).

A teoria dos atores com poder de veto de George Tsebelis é identificada como seminal na Ciência Política (BROUARD; HONNIGE; 2017), pelo amplo espectro de possibilidade de aplicação da sua metodologia. Além da amplitude, um grande contributo do seu trabalho é a possibilidade de uma reflexão sobre os modelos institucionais em funcionamento a partir da ação dos seus principais atores.

Para concluir este tópico, serão expostos dois trabalhos que dialogam, ou se utilizam, da metodologia dos atores com poder de veto de George Tsebelis aplicada ao Poder Judiciário, Courts as veto player, a Game-Theoretic model (2013), de Benjamin G. Engst, Caroline E. Wittig, Cristoph Hönnige e Thomas Gsch, e o artigo Constitutional courts as veto players: lessons from the United States, France and Germany (2017), de Sylvain Brouard e Cristoph Hönnige.

O primeiro texto estabelece um diálogo com a obra de George Tsebelis, objetivando aprofundar as análises sobre o poder judiciário. Tal esforço é desenvolvido na busca do 
preenchimento de uma lacuna na tradição de pesquisa sobre Cortes Constitucionais na Europa e nos EUA, como também com o objetivo de uma maior compreensão da denominada caixa preta que envolve o Poder Judiciário, indicando elementos específicos da organização institucional de tal poder.

Segundo os autores a tradição europeia de pesquisas sobre as cortes constitucionais tende a valorizar as relações interinstitucionais da cúpula do Poder Judiciário com os demais atores do sistema político, por outro lado a tradição norte-americana sobrevaloriza as preferências políticas dos membros do Poder Judiciário como aspecto preponderante para a compreensão da instituição, seja pelos trabalhos de análise atitudinal, ou institucional. Neste ponto, os autores indicam a existência de um espaço a ser preenchido pela pesquisa, que considere a relação entre as preferências políticas dos juízes e o comportamento institucional e estratégico do Poder Judiciário.

Outro aspecto particularmente importante no texto Courts as veto player - a GameTheoretic model encontra-se na diferenciação que os autores fazem do método de controle concentrado de constitucionalidade (kelseniano) e o modelo difuso norte-americano caracterizado pelo judicial review. Conforme os autores indicam, as diferenças dos desenhos institucionais de cada um destes modelos podem implicar em variáveis na atuação dos seus atores.

Além disto, tal trabalho também enfoca o papel dos desenhos institucionais de cada modelo na atuação do Poder Judiciário, com ênfase para os juízos de admissibilidade e de mérito no controle de constitucionalidade, além da possibilidade de julgar reclamações constitucionais pelo descumprimento de suas decisões.

O argumento principal dos autores é que o Poder Judiciário não é absorvido no exercício do seu poder de veto, diferentemente do pressuposto defendido por Robert Dahl e George Tsebelis, pelo contrário, em função do papel desempenhado, ora como instituição independente responsável pela guarda da Constituição e ora como ator político interessado, o Poder Judiciário deve ser identificado como um ator com poder de veto com grande importância estratégica:

These features make courts strong veto players in the multifaceted interaction between the plaintiff, the government, and the judiciary. And it appears that plaintiffs are servants to the constitutional court allowing the judges to enhance policy in their interest. (ENGST, et al, 2013) ${ }^{6}$

Nesta perspectiva, mitigar a importância do órgão que decide sobre as regras do jogo, ou considera-lo como um autômato despido de interesses políticos e incapaz de formular estratégias

\footnotetext{
6 Tradução livre: "Essas características fazem dos tribunais fortes atores com poder de veto na interação multifacetada entre os demandantes, o governo e o judiciário. E parece que os demandantes são servidores do tribunal constitucional permitindo aos juízes melhorar a política no seu interesse.” (ENGST, et al, 2013)
} 
na busca de seus objetivos é uma perspectiva que pode resultar em grave comprometimento da compreensão da atuação do Poder Judiciário no sistema político.

O segundo texto é menos propositivo e mais criterioso na aplicação da metodologia de George Tsebelis para a compreensão das Cortes Constitucionais como atores com poder de veto, a análise envolve os tribunais dos EUA, França e Alemanha. Este trabalho possuí uma base empírica mais clara do que o anteriormente exposto, envolvendo o lapso temporal entre 1974 e 2009.

Mais uma vez a diferenciação entre o controle difuso e o controle concentrado fica exposta entre os aspectos organizacionais de cada um destes países, como também o questionamento se o Poder Judiciário é um ator com poder de veto absorvido no sistema político. Os autores analisam estas questões a partir de três indicadores:

First, some judges on constitutional courtes are not selected by other VPs and are thefore nor absorved. Second, even they are entirely appointed by other VPs, they might initially be absorved, but absorption might end after a change in te pattern of government control. And third, even if they are located centrally in terms of policy, they might not be absorbed as a result of varying legislative procedures (BROUARD, HÖNNIGE, 2017, p. 532). ${ }^{7}$

Os dados indicaram que a Suprema Corte dos EUA exerceu com menor frequência o poder de veto do que o Conselho Constitucional da França e o Corte Constitucional da Alemanha, possibilitando o questionamento se o desenho constitucional do controle difuso, efetivamente, enseja uma maior proximidade e composição do Poder Judiciário ao núcleo de unanimidade como pressupunham Robert Dahl e George Tsebelis, dois analistas do modelo norte-americano.

Por outro lado, as variáveis apresentadas pelos autores indicam a impossibilidade de generalização do alinhamento do Poder Judiciário aos demais poderes da república, a uma porque a mudança de governo por decorrência dos resultados eleitorais pode apresentar disfunções entre composições das Cortes indicadas pelo governo anterior e a composição majoritária atual do governo, a duas porque diferenças procedimentais no processo legislativo podem impactar a atuação do Poder Judiciário como ator com poder de veto.

Os resultados são deveras interessantes e indicam dois pontos relevantes para o presente trabalho, a aplicabilidade da metodologia desenvolvida por George Tsebelis, alguns limites deste

\footnotetext{
7 Tradução livre:

"Primeiro, alguns juízes de cortes constitucionais não são selecionados por outros atores com poder de veto e não são precedidos nem absorvidos. Em segundo lugar, mesmo que sejam totalmente nomeados por outros atores com poder de veto, eles podem inicialmente ser absorvidos, mas a absorção pode terminar após uma mudança no padrão de controle do governo. E terceiro, mesmo se eles estiverem localizados centralmente em termos de política, eles podem não ser absorvidos como decorrência de mudanças dos processos legislativos.“(BROUARD, HÖNNIGE, 2017, p. 532).
} 
arcabouço teórico, e elementos relevantes para a sua aplicação no estudo das cortes constitucionais pelas ciências jurídicas.

Feita esta exposição, no próximo tópico analisaremos as possibilidades de aplicação da metodologia supracitada para pesquisas jurídicas sobre a atuação do Supremo Tribunal Federal no modelo constitucional instituído em 1988.

\subsection{O Poder Judiciário como ator com poder de veto}

Desde a promulgação da Constituição Federal de 1988 o Poder Judiciário tem ganho destaque como objeto de estudo, se no Brasil tal tema pode ser caracterizado como de interesse recente em outros países a produção acadêmica sobre o assunto já acumula décadas de debate.

Um bom exemplo é a produção norte-americana sobre o processo decisório da Suprema Corte, os debates originários são indicados já na década de 30 do século XX, a partir das primeiras análises sobre realismo jurídico. Desde então é possível indicar uma profusão de explicações e metodologias sobre o funcionamento do Poder Judiciário naquele país que, por ser uma influência institucional em âmbito global, torna tal produção incontornável para os pesquisadores da área.

Assim, um bom caminho para as pesquisas desenvolvidas no Brasil sobre o Poder Judiciário e o Supremo Tribunal Federal é acompanhar com atenção os principais resultados, impasses e soluções encontradas em outros países com mais tradição neste campo. Não para reproduzir acríticamente metodologias importadas para análises das instituições jurídicas nacionais, mas, ao menos, para evitar os erros já cometidos e considerados improdutivos (RIBEIRO; ARGUEHLHES; 1998).

Muito sucintamente, é possível indicar, para fins didáticos, três concepções predominantes na doutrina da ciência política norte-americana sobre análise do poder judiciário, com destaque para a revisão bibliográfica feita por Celly Cook Inatomi:

\footnotetext{
Abordagens de cunho individualista: com enfoque no comportamento político dos juízes, destacadamente análises como o behaviorismo, mais localizada no âmbito da ciência política, e possuindo como ideia central a análise política do Poder Judiciário, por meio do modelo atitudinal e do modelo estratégico;

Abordagens de cunho estruturalista: com destaque para a função do direito e do Poder Judiciário nas estruturas de poder, possui como referência principal de análise as condicionantes sociais, culturais e históricas que ordena e/articula as relações entre os indivíduos e as relações destes com as instituições.

Abordagens de cunho institucionalista: Analisa as regras e formas de funcionamento do Poder Judiciário, na condição de instituições com poder coercitivo sobre os atores políticos. Atualmente, o denominado neoinstitucionalismo já considera a relação entre instituições e os sujeitos que as integram. (2017, p. 102-127)
} 
Ainda que a produção supracitada tenha como referência epistemológica a Ciência Política, tal como ocorre no debate norte-americano, e em muitos países, os ramos distintos das ciências sociais tendem a exercer influências recíprocas entre si, tratando-se de um diálogo a ser estimulado. Isto porque o isolamento de uma ciência, por exemplo, a ciência jurídica, não se apresenta mais compatível com a complexidade dos objetos de análise do século XXI.

Neste ponto, os questionamentos devem ser endereçados sobre quais as características predominantes de uma metodologia no âmbito da ciência jurídica, ou da ciência política, e não se evitar a interlocução, que corre o sério risco de ser absolutamente empobrecedora não apenas do diálogo entre as diferentes ciências, como também da ciência jurídica em si mesma. Reforçamos, o reconhecimento e a identificação da riqueza metodológica da ciência política é algo que favorece a delimitação de fronteiras epistêmicas, no que for necessário, e contribui para a identificação dos objetos e metodologias específicas das ciências jurídicas.

O trabalho de George Tsebelis possui claros elementos de uma análise institucionalista contemporânea, caracterizada por conceber uma relação de dupla influência entre as instituições e os atores que as integram, como também pode fornecer um aporte teórico para análises realistas das instituições em funcionamento e em interação entre si, como é o caso do presente artigo.

Considerando a classificação apresentada sobre os atores com poder de veto, inicialmente, vale indicar um ponto de complexidade desta classificação para a compreensão do funcionamento do Supremo Tribunal Federal, pois em que pese se trate de um colegiado pesquisas empíricas recorrentes tem indicado que se trata de um órgão com uma expressiva atuação na condição de um ator com poder de veto individual. Em realidade, e este é o ponto de complexidade, ora a instituição atua como um ator individual e ora como um ator coletivo.

Tradicionalmente, as pesquisas sobre a atuação do Supremo Tribunal Federal enfatizaram as decisões colegiadas, sob o argumento que as decisões individuais seriam sufragadas posteriormente pelo colegiado.

Em artigo recente Arguelhes e Ribeiro dialogam com esta tradição e partem dos estudos de Oscar Vilhena sobre o fenômeno denominado de Supremocracia para apontar elementos que justificam uma análise mais cuidadosa sobre as atuações individuais dos membros do Supremo Tribunal Federal, apontando para o fenômeno denominado de Ministocracia (2018).

Em que pese a relação entre decisões individuais e colegiadas seja de controle no desenho institucional do Supremo Tribunal Federal, pesquisas empíricas indicam a existência de um significativo lapso temporal entre concessão de liminares e análise de mérito pelo colegiado, como também inúmeras situações nas quais ocorre a perda do objeto, de modo que o controle da decisão monocrática pelo colegiado resulta prejudicado: 
Entre 2007 e 2016, passaram-se em média 1.278 dias entre uma decisão liminar monocrática, em controle concentrado, e a primeira oportunidade de manifestação colegiada no mesmo processo.31 Considerando-se apenas as decisões concessivas de liminares, a média é de 797 dias. Para além do controle concentrado, considerando todas as classes processuais no período de 2012 a 2016, passaramse em média 617 dias entre a concessão monocrática de uma medida liminar e a primeira oportunidade de apreciação por um colegiado. No mesmo período, nos casos em que a liminar monocrática concessiva foi seguida de uma decisão declarando o julgamento prejudicado, o tempo de vigência da referida liminar foi, na média, de 767 dias (ARGUELHES; RIBEIRO, 2018, p. 24).

Assim, é necessário que a metodologia da pesquisa empírica dê conta desta diferenciação, porque a mesma pode ser relevante por possibilitar formulações de perguntas e respostas sobre os seguintes temas, por exemplo: Quando atua como ator individual o Supremo Tribunal Federal exerce mais ativamente o poder de veto do que quando atua em na condição de órgão colegiado ${ }^{8}$

Um segundo ponto a ser considerado refere-se ao poder de agenda na arena decisória, tal poder diz respeito aqueles atores que possuem a competência jurídica, ou autoridade política, de pautar um tema específico, ou impedir que tal tema seja colocado em pauta.

Particularmente, na aproximação da metodologia de George Tsebelis para análise do Supremo Tribunal Federal importa destacar a existência de duas arenas decisórias distintas, ainda que umbilicalmente conexas, quais sejam, a esfera da política ordinariamente em trâmite no Congresso Nacional e a arena judicial que ocorre no Supremo Tribunal Federal.

No primeiro caso, agenda política, o poder de agenda por parte do Supremo Tribunal Federal é praticamente inexistente. No referente ao poder de agenda no âmbito interno existe um interesse acadêmico crescente sobre as formas de composição da pauta da corte.

Atualmente existe um consenso sobre a ausência de clareza no que diz respeito ao poder de agenda $^{9}$ no Supremo Tribunal Federal, pois as poucas regras formais sobre o tema não são observadas rigorosamente no seu funcionamento cotidiano, como também a mudança periódica da presidência do tribunal tem resultado em alterações em relação as regras existentes sobre a organização da pauta (DIMOULIS; LUNARDI; 2012).

Isto possui uma importância fundamental nas relações entre os atores do sistema político, constituindo-se em variável em análises sobre a atuação da corte, tal questão corrobora

\footnotetext{
${ }^{8}$ Vale destacar que sobre esta variável ainda caberia mais um recorte, referente ao comportamento das turmas componentes do Supremo Tribunal Federal. Assim, teríamos três recortes, decisões individuais, decisões colegiadas das turmas e decisões colegiadas do pleno.

${ }^{9} \mathrm{O}$ debate sobre o poder de agenda também é passível de ser relacionado com a variável antes apontada em relação as decisões individuais ou coletivas do Supremo Tribunal Federal, isto porque o processo que é submetido à uma decisão liminar fica em poder do seu relator que decidirá quando o mesmo será colocado em pauta, o que pode significar um significativo poder de agenda na relação entre ministro e colegiados.(ARGUELHES; RIBEIRO; 2018)
} 
absolutamente para a denominação de George Tsebelis do Poder Judiciário como uma caixa preta, pela ausência de clareza sobre procedimentos fundamentais na atuação dos atores envolvidos.

Como terceiro ponto de aproximação, destacamos a singularidade do modelo de controle de constitucionalidade brasileiro que acumula no Supremo Tribunal Federal tanto competência do controle concentrado, como também do controle difuso de constitucionalidade.

Neste aspecto temos um elemento para considerar a especificidade da análise proposta como singular às ciências jurídicas, porque cada um dos modelos, concentrado ou difuso, possui regras processuais e procedimentais próprias que servem como parâmetro decisório para o Supremo Tribunal Federal. Mesmo que eventualmente tais parâmetros não sejam observados, não podemos desconsiderar suas características.

No controle concentrado a utilização das Ações Diretas é regulada pela competência originária prevista no artigo 103, I, da Constituição Federal de 1988, e pelas leis 9868/99 e a lei 9882/99, com juízos de admissibilidade e de mérito distintos daqueles previstos para o exercício do controle difuso regulado, por sua vez, pelo Art. 103, II, da Constituição Federal de 1988 e pelo Novo Código Civil, com juízos de admissibilidade como a necessidade de comprovação de repercussão geral do recurso extraordinário, a fundamentação vinculada e os efeitos da decisão, em regra, serem apenas entre as partes.

Assim, surgem questionamentos relevantes sobre o impacto das instituições do controle de constitucionalidade no comportamento judicial da corte, a partir de questionamentos se a variável institucional enseja maior ou menos exercício do poder de veto pelo Supremo Tribunal Federal a depender do acionamento via controle concentrado ou via controle difuso.

Este ponto pode ser contributivo para análises sobre como as instituições estruturam o comportamento dos juízes, particularmente no diálogo entre os defensores do modelo atitudinal e os defensores do modelos legal, pois se o Supremo Tribunal Federal apresenta em uma mesma composição resultados empíricos em sentidos diversos sobre o exercício do poder de veto no controle concentrado e no controle difuso de constitucionalidade, tais elementos podem corroborar para a formulação de problemas e hipóteses sobre a influência das instituições jurídicas na forma como os juízes decidem, para além de uma expressão das suas preferências políticas.

Neste sentido, outro aspecto a se considerar sobre as possibilidades de análise do Supremo Tribunal Federal como ator com poder de veto como objeto de análise das ciências jurídicas diz respeito ao denominado princípio da inércia da jurisdição, isto é, a corte apenas atua quando acionada e a decisão sobre a forma de seu acionamento não pertence ao Poder Judiciário, mas sim as demais atores com legitimidade ativa para tal. 
Assim, ainda que seja inquestionável a amplitude decisória da corte, o fato do seu acionamento ser externo, como também a opção por qual modelo ocorrer tal acionamento indica que se trata de um ator que precisa se adaptar a condicionantes sobre as quais ele não possui poder de decisão. Disto resulta a necessidade de elaboração de metodologias para a compressão das especificidades das análises sobre o Poder Judiciário.

Justamente desta perspectiva decorre a classificação do Supremo Tribunal Federal como ator com poder de veto informal, e não formal, pois a possibilidade de obstrução à mudança legislativa não é inerente ao processo legislativo previsto na Constituição Federal de 1988. E depende da iniciativa de outros atores não pertencentes ao Poder Judiciário, que decidirão, inclusive, quais as instituições serão utilizadas para o acionamento desta possibilidade de exercício do veto.

Por fim, uma classificação recorrente na doutrina brasileira considera o momento da decisão sobre o exercício do poder de veto, se preventivo, antes da promulgação do projeto de lei considerado inconstitucional, ou após a sua promulgação, em exercício repressivo do controle de constitucionalidade.

Na perspectiva teórica dos atores com poder de veto, o principal diferencial desta hipótese é a obstrução do próprio debate político que se verifica no exercício preventivo do controle de constitucionalidade, do que nos possibilitaria afirmar que o veto incide sobre o debate político e o exercício da representação. Por outro lado, em sendo um veto repressivo, ocorre uma caracterização mais claro da sua incidência à norma jurídica que apresenta vícios de inconstitucionalidade em sentido formal ou material.

Com isto, apresentamos em caráter exploratório alguns elementos que possibilitam a aproximação do estudo sobre a atuação do Supremo Tribunal Federal como ator com poder de veto a partir do referencial teórico de George Tsebelis.

\section{Conclusão}

No presente trabalho foi apresentada a proposta de análise institucional dos atores com poder de veto como possibilidade de um marco teórico para pesquisas sobre o funcionamento do Supremo Tribunal Federal no desenho definido pela Constituição Federal de 1988.

Os resultados apresentados são positivos, seja porque o aporte teórico testado possui como característica análises realistas das instituições e as suas categorias são típicas para pesquisas sobre os Estados contemporâneos, como também porque já existem trabalhos produzidos ou em desenvolvimento em outros países que podem servir como referência para a aplicação de tal 
metodologia nos estudos sobre a atuação do Supremo Tribunal Federal no sistema político brasileiro.

Em relação ao Poder Judiciário, deve-se prevenir, as Cortes Constitucionais apresentam características específicas, comparativamente, ao Poder Legislativo e ao Poder Executivo, do que resulta a necessidade de adaptações metodológicas para melhor desempenho analítico de tal marco teórico.

Tais adequações visam o equacionamento das diferenças do Poder Judiciário em relação ao Poder Legislativo e o Poder Executivo, marcadamente no que se refere a manifestação das preferências políticas e seu impacto nos processos decisórios dos atores. No Poder Legislativo e no Poder Executivo o conceito de representação política indica fortes elementos de influência no comportamento dos atores envolvidos, por outro lado, no Poder Judiciário, a forma de ingresso por concurso público nas instâncias inferiores, como também o procedimento de indicação e nomeação para as Cortes Superiores não expressam com clareza quais são as variáveis predominantes na atuação dos juízes e tribunais.

Justamente por este motivo, George Tsebelis não aprofunda seus estudos em relação ao Poder Judiciário e denomina tais dificuldades de compreensão como uma caixa preta (black box). Isto afirma que a metodologia utilizada precisa de adaptações, e que a mesma é passível de utilização no campo predominante das ciências jurídicas, sem desconsiderar o diálogo e as influências recíprocas com os demais ramos do conhecimento.

Assim, é possível concluir que a obstrução apresentada por Tsebelis do Poder Judiciário ser uma caixa preta como dificuldade de sua análise não é insuperável, mas expõe limites inegáveis às possibilidades de descrição deste objeto, que se por um lado não apresenta uma racionalidade ótima em todas as suas ações, por outro enseja a compreensão das suas formas de interação nas relações inter-institucionais.

Neste ponto, as formas processuais e procedimentais estabelecidas pela Constituição Federal de 1988 e pela legislação correlata apresentam inegável campo de exploração científica para pesquisadores da área do Direito, sobretudo em pesquisas sobre como as instituições influenciam o comportamento dos juízes e dos tribunais.

A forma de indicação para a composição dos ministros do Supremo Tribunal Federal e seus reflexos no exercício do poder de veto apresenta-se como pertinente problema investigativo a ser desenvolvido, possibilitando ainda a bifurcação diferencial entre o âmbito do controle concentrado e o controle difuso de constitucionalidade.

Desde modo, importa assinalar que o principal objetivo deste artigo de apresentar a obra de George Tsebelis e indicar sua pertinência para pesquisas nas ciências jurídicas foi concluso de 
forma satisfatória, sem descurar da pertinência de maior aprofundamento na aplicação da metodologia apresentada.

\title{
SUPREME FEDERAL COURT LIKE VETO PLAYER: AN ANALYSIS FROM THE WORK OF GEORGE TSEBELIS.
}

\begin{abstract}
This article has as its theme methodologies for examining constitutional courts in the field of constitutional law, in interdisciplinary reading with political science. In detail, studies on the operation and performance of the Federal Supreme Court in Brazil, considering the design of the Federal Constitution of 1988. The problem deals with the possibility of identification of the Supreme Court as a veto player, having as methodological theoretical reference the work of George Tsebelis. The hypothesis considers possible such a methodological option, and aims to identify its analytical potential for understanding the relations between the powers of the Republic in the contemporary Brazilian state. The method used is bibliographic, with institutional analyses, resulting in the conclusion of the broad possibility of application of such a theoretical milestone, as well as the need for some precautions to improve their analytical potential in relation to the power Judiciary.
\end{abstract}

Keywords: Supreme Court in Brazil - Veto - Player - Jurisdiction - Constitution

\section{Referencias bibliográficas}

ARGUELHES, Diego Werneck. RIBEIRO, Leandro Molhano. O Supremo Tribunal individual e o processo democrático brasileiro. In: Novos Estudos CEBRAP. V.37. N.01. Jan.Abr. São Paulo: CEBRAP, 2018, p. 13-32.

BROUARD, Silvain; HÖNNIGE, Christoph. "Constitutional Courts as Veto Players: Lessons from the United States, France and Germany”. European Journal of Political Research, v. 56, pp. 529$552,2017$.

DAHL, Robert Alan. "Decision-Making in a Democracy: The Supreme Court as a National PolicyMaker". Journal of Public Law, n. 6, pp. 279-295, 1957.

DIMOULIS, Dimitri. LUNARDI, Sonia. O poder de quem define a pauta do STF. In: Os constitucionalistas. http://www.osconstitucionalistas.com.br/o-poder-de-quem-define-a-pauta-dostf, acesso no dia 02 de setembro de 2018.

ELSTER, Jon. Peças e engrenagens das ciências sociais. Rio de Janeiro: Relume-Dumará, 1994.

INATOMI, Celly Cook. Abordagens teóricas na pesquisa empírica sobre o Poder Judiciário: Diálogos, pontes, híbridos. In: KOERNER, Andrei (org). Política e Direito na Suprema Corte Norte Americana. Ponta Grossa: UEPG, 2017, p. 99 - 142. 
KOERNER, Andrei. O debate norte-americano sobre as relações entre instituições, decisão judicial e análise do pensamento jurídico. In: KOERNER, Andrei (org). Política e Direito na Suprema Corte Norte Americana. Ponta Grossa: UEPG, 2017, p. 59-98.

KRIZER, Hebert. RICHARDS, Mark., "The Influence of Law in the Supreme Court's SearchandSeizure Jurisprudence". America Politics Research, 33, 1: 2005, p. 33-55.

OLIVEIRA, Cláudio Ladeira de. Moralidade e jurisdição: a compreensão procedimentalista do Direito em Jurgen Habermas. Tese de Doutorado. Florianópolis: Universidade Federal de Santa Catarina, 2006, p. 338.

Ativismo judicial, moderação e o minimalismo judicial de Cass Sunstein. In: XVI Encontro Preparatório para o Congresso Nacional do CONPEDI (Conselho Nacional de Pesquisa e Pós-Graduação em Direito, 2007, Campos dos Goytacazes. Anais do XVI Encontro Preparatório para o Congresso Nacional do CONPEDI. Florianópolis: Fundação Boiteux, 2007. v. único. p. 1384-1404.

RIBEIRO, Leandro Molhano; ARGUELHES, Diego Werneck. "Preferências, estratégias e motivações: pressupostos institucionais de teorias sobre comportamento judicial e sua transposição para o caso brasileiro". Direito e Práxis, v. 4, n. 7, pp. 85-121, 2013.

REIS, Fabio Wanderley. Mercado e Utopia: sociedade brasileira. São Paulo: Editora Universidade de São Paulo, 2000.

TSEBELIS, George. Jogos ocultos: escolha racional no campo da política. São Paulo: Editora da Universidade de São Paulo, 1998.

Janeiro: Editora FGV, 2009.

Atores com poder de veto: como funcionam as instituições políticas. Rio de

Trabalho enviado em 22 de janeiro de 2019

Aceito em 17 de março de 2019 